\title{
ABORDAGEM ANALÓGICA SOBRE A "NAUTILUS HOUSE": INTERPRETAÇÃO ARQUITETÔNICA SOBRE CONCEITO TEATRAL E CONCEITO MATEMÁTICO
}

\author{
Korina Costa, Bruna Fagliari Sposito, Vivian lamassaki. \\ Universidade do Oeste Paulista - UNOESTE, Especialização em Projeto Arquitetônico, Presidente Prudente, \\ SP.
}

\begin{abstract}
RESUMO
Conhecer a história da arquitetura e suas características é de grande importância para o desenvolvimento de uma análise de interpretação de projetos, os quais, pertencem à uma vasta ideologia de conceitos. O presente trabalho apresenta uma análise analógica dos conceitos Teatral e Matemático, aplicados no projeto arquitetônico Nautilus House de Javier Senosiain: uma residência unifamiliar implantada num bairro residencial da cidade do México, no qual transfigura a idéia de uma moradia, para dentro de uma forma inusitada. A arquitetura toma a forma da concha do molusco Náutilus, no qual dá nome à casa. As análises foram desenvolvidas baseadas nos levantamentos bibliográficos realizados, enfatizando as percepções sobre as características apresentadas pela residência, que traduziam os conceitos apresentados, por base de análise de imagens.
\end{abstract}

Palavras-chave: Casa Náutilus, Javier Senosiain, Bio-aquitetura, Analogia Teatral, Analogia Matemática.

\section{APPROACH ANALOG ABOUT THE "NAUTILUS HOUSE": INTERPRETATION ARCHITECTURAL ABOUT THEATRICAL AND MATHEMATICAL CONCEPT}

\begin{abstract}
Knowing the history of architecture and its characteristics is very important for the development of a project interpretation analysis, which belong to a broad concept of ideology. This work presents an analog analysis of Theatrical and Mathematical Concepts, applied in the architectural project Nautilus House of Javier Senosiain: a single family residence located in a residential district of Mexico City, in which transfigures the idea of a house, into a unusual form. The architecture takes the clam shell shape Nautilus, which gives its name to the house. The Analysis were developed based on bibliographic surveys, emphasizing perceptions of the features presented by the residence, which reflected the concepts presented, based on image analysis.

Key worlds: Nautilus House, Javier Senosiain, Bio-architecture, Theatrical analogy, Mathematical analogy.
\end{abstract}




\section{INTRODUÇÃO}

Por toda a história as arquiteturas produzidas passaram por períodos e fases diferentes que as distinguiram, de certa forma, uma das outras, seja pelo material empregado, pela técnica construtiva, entre outras coisas. Assim, desde as civilizações mais antigas até a contemporaneidade cada período na história da arquitetura produziu uma série de elementos que o fez de característico para tal, como exemplo, a aplicação matemática do retângulo áureo na arquitetura clássica grega, os arcos e abóbodas ogivais na arquitetura gótica e o traçado limpo e geométrico na arquitetura moderna. Mas estas foram características resultantes dos recursos que cada época e civilização possuía naquele determinado momento, ou seja, das técnicas construtivas utilizadas ZEVI (1996).

Porém cada arquitetura produzida continha em seu ato projetual e/ou construtivo, um conceito que em si carregava a essência a ser alcançada, tido com o seu caráter e que pode ser definido como "um pensamento que se refere à maneira como vários elementos ou características podem ser combinados numa coisa única" (SNYDER; CATANESE, 1984, p. 216). Assim, cada arquitetura possuiu o seu diferencial.

Mas não somente baseada em um único conceito as arquiteturas podem ser definidas. $E$ este artigo, terá por objetivo demonstrar que uma obra arquitetônica pode estar envolvida em diferentes conceitos. Como no caso da Nautilus House, do arquiteto mexicano Javier Senosiain, que foi estudada através da aplicação de uma abordagem de análise sobre conceitos analógicos, como resultado da integração dos conceitos teatral e matemático em sua composição.

\section{METODOLOGIA}

A presente pesquisa é do tipo quantitativa e tomou como base os levantamentos bibliográficos, buscando compreender os conceitos relativos ao tema abordado e a formulação de um estudo comparativo das analogias referenciadas pela obra arquitetônica Nautilus House, nosso objeto de estudo. Os estudos em relação às analogias foram realizados através de levantamento bibliográfico, pautados assim, nas discussões teóricas e conceituais sobre as teorias de estudo arquitetônico e de levantamento imagético e documental, para a efetuação de análises comparativas entre as características das diferentes analogias, conforme encontradas na obra arquitetônica.

O que segundo Bogdan e Biklen (1982) apud André e Ludke (1986, p. 13) "envolve a obtenção de dados descritivos, obtidos no contato direto do pesquisador com a situação estudada, enfatiza mais o processo do que o produto", sendo evidente e significativa a leitura própria e singular do pesquisador sobre como os conceitos teóricos se concretizam no estudo desenvolvido.

"Os focos de observação nas abordagens qualitativas de pesquisa são determinados basicamente pelos propósitos específicos do estudo, que por sua vez derivam de um quadro teórico geral, traçado pelo pesquisador [...] Segundo Bogdan e Biklen, o conteúdo das observações deve envolver uma parte descritiva e uma parte mais reflexiva" (ANDRÉ; LUDKE, 1986, p. 30).

\section{DISCUSSÃO SOBRE AS INTERPRETAÇÕES E CONCEITOS NA ARQUITETURA}

Ao se retomar a história das arquiteturas, é visto que de período a período muitas das obras realizadas, quase sempre, apresentam mudanças arquitetônicas acarretadas pela busca do rompimento daquilo que se estava produzindo até então. Seja por motivos políticos, econômicos ou sociais, buscava-se sempre o novo a cada passar de tempos - permitido em sua maioria pela descoberta de novas tecnologias - ou somente em romper aquelas que estavam sendo produzidas. Sobre seus princípios de criação, porém, entre as idas e vindas de períodos, as arquiteturas nunca fugiram do seu papel fundamental de fornecer proteção ou abrigo, e, querendo ou não, elas 
sempre retornam com algo que se remetia à algum outro período anterior que já se passara, de forma aparentemente diferente, porém com mesma essência de uso, como os pilotis modernistas relendo os pilares da arquitetura clássica, porém apenas na sua constituição primordial, aquela que diz respeito apenas à sua função estrutural, não fazendo referências aos demais elementos contidos nas ordens clássicas (JANSON, 2001).

Diante às diversidades produzidas, teóricos tentaram criar modelos de interpretação para analisar as arquiteturas de forma à classifica-las perante sua composição formal. No período moderno, porém, quando o espaço interno era de fundamental importância no processo de criação, quando "forma segue a função" - célebre frase de Louis Sullivan (FRAMPTON, p. 58) - o teórico Bruno Zevi (1996, p. 139) afirma que tais interpretações criadas pelos críticos apenas pela forma, não eram corretas. De acordo com o mesmo autor, para se interpretar um estilo de arquitetura, não se deve apontar um elemento específico para dizê-lo que é ele que a determina: como afirmar que a "Catedral de Wells é arquitetonicamente determinada pela técnica construtiva dos arcos ogivais e arcobotantes e das abóbodas em guarda-chuva", onde a técnica seria como "uma interpretação autêntica, aplicável a todos os monumentos da arquitetura" (ZEVI, 1996, p. 139).

Sendo naturalmente mais significativa em alguns períodos, como a civilização grega, o gótico e o funcionalismo, enquanto abrangerá aspectos secundários do mundo cristão, da Renascença ou da moderna tendência orgânica, onde mesmo a técnica sendo levado ao mais alto índice das interpretações, como Zevi (1996) revela, nenhuma arquitetura foge do seu significado mais íntimo, aquele pelo qual a deu forma. E quando esta arquitetura é interpretada unicamente, na tentativa de compreendê-la, do por que ela foi projetada daquela forma; ou o que se pretendia; e quais as sensações eram buscadas, então se tem os conceitos arquitetônicos.

De acordo com Snyder e Catanese (1984, p. 210) "uma definição simples de conceito sugere que conceito são ideias que integram vários elementos num todo. [...] Em arquitetura, conceito sugere um modo específico de conjugar exigências programáticas, contextos e crenças." Segundo os mesmos autores:

"Há cinco tipos de conceitos: analogias (olhando para outras coisas), metáforas (olhando para abstrações), essências (olhando para além das necessidades programáticas), conceitos programáticos (olhando para os requisitos declarados) e ideais (olhando para valoreis universais) (SNYDER; CATANESE, 1984, p. 223)

O conceito por meio de analogias, segundo os mesmos autores, são os mais frequentemente utilizados, já que "analogias identificam relações possíveis e literais entre coisas. Uma coisa é identificada como tendo todas as características desejadas, e assim se torna um modelo para o projeto em mãos" (SNYDER E CATANESE 1984, p. 223 ). Os autores ainda revelam, como exemplo, o pensamento de arquitetos anteriores ao período moderno quando se acreditava que todos os modelos de arquitetura já haviam sido criados, e então bastava relacionar, diante a história, qual edifício era característico para seu uso, como exemplo, "num certo momento jugouse que o gótico era o modelo apropriado para igrejas e universidades" (SNYDER; CATANESE, 1984, pg 223).

Dentre as analogias tem-se os seguintes conceitos: Conceito Matemático; Conceito Mecânico; Conceito Biológico; Conceito Romântico; Conceito Teatral; Conceito Musical; Conceito Sistêmico; Conceito Tipológico; Conceito Linguístico e Conceito Existencial. A partir destes, os conceitos Teatral e Matemático servirão de base de análise, da obra arquitetônica que será apresentada a seguir. 


\section{RESULTADOS OBTIDOS PELO ESTUDO DA NAUTILUS HOUSE}

Localizada em Naucaplan de Juarez, México, a Casa Náutilos (2006-2007) foi desenvolvida pelo arquiteto mexicano Javier Senosiain, a obra possui design não usual. Inspirado pelo trabalho de Gaudí e Frank Lloyd Wright, Senosiain trouxe um brilhante exemplo do que ele chama de "bioarquitetura" - a ideia de prédios baseados nos princípios naturais de formas orgânicas, vale destacar que ela foi projetada para um casal e seus dois filhos, a casa encontra-se totalmente integrada com seu entorno (ARCHITECTUREARTDESIGNS, 2016).

O arquiteto explica que desde os primeiros croquis de implantação, o fundo da propriedade foi definido, deixando a frente para o acesso de pessoas e veículos. As formas arredondadas de sua arquitetura reinterpretam as conchas dos náutilos, cefalópode que dá nome a residência. Essa concha, além de inspirar proteção, é sinônimo de perfeição, pois sua espiral corresponde a um logaritmo matemático. Cuja forma inconstante da casa conta com uma escultural parede de vidros coloridos cuja visão a faz atrativa desde o exterior. Para entrar é preciso subir uma escada e ao passar por essa parede, o que gera uma experiência espacial onde nem as paredes, nem o piso e nem o teto são paralelos. Os caminhos que percorrem a sala principal estão recobertos por pedras naturais. (ES.WIKIARQUITECTURA, 2015).

Na construção da Casa Náutilos foi utilizado o ferrocimento, este material é composto por uma malha de aço distribuída transversalmente e revestido com uma mistura de betão especial, com aproximadamente cinco centímetros de espessura. Essa técnica permite curvas arredondadas e naturais, evitando a necessidade de muros de carga ou pilares. O que da rigidez estrutural, é a forma espiral contínua transversal da dupla curvatura. Para ventilação, foram colocados no subsolo duas passagens que permitem a entrada de ar do exterior. (ES.WIKIARQUITECTURA, 2015).

\section{ANALOGIA SOBRE O CONCEITO TEATRAL}

Também chamado de dramatúrgico, vê a arquitetura como palco (espaço cenográfico), onde as pessoas representam papéis; assim os ambientes tornam-se cenários, que suportam o espetáculo da vida. A principal preocupação é fornecer aos usuários suportes e cenários para desempenharem papéis ou dirigirem a ação, como propõe os arquitetos pós modernos formalistas, das décadas de 1970 e 1980. (SNYDER; CATANESE, 1984)

Assim, a arquitetura vai buscar a exploração de efeitos e elementos que a transformem numa dramaturgia. Nas composições cenográficas teatrais, muito se diz à respeito da apropriação do espaço e da criação do lugar (URSSI, 2006).

Segundo Urssi (2006, pg. 78) o conceito de espaço "enquanto qualidade cênica da superfície e ambientes disponíveis no espetáculo", pode ser definido pelo seu espaço geométrico que, segundo o autor, é "a distância entre objetos, existentes ou possíveis, de extensão abstrata e significado subjetivo, em uma, duas ou três dimensões. "

Na Casa Náutilos, esse espaço geométrico pode ser visualizado na composição de seu interior, que foi projetado seguindo suas curvas imprevisíveis. O mobiliário "nasce" do piso e das paredes em formatos orgânicos moldados com o mesmo material da residência em locais já determinados pelo arquiteto, (a mobília é fixa) parecendo objetos cenográficos, assim como os jardins e degraus.

Em casa, nada é paralelo. Nem as paredes, nem mesmo o chão. 0 arquitecto refere que viver aqui é uma experiência a três dimensões, num ambiente tranquilo e fluido, dominado pelas formas curvas e algumas surpresas. Por exemplo, a sala de estar emerge desde o interior do jardim e a mesa da sala de jantar é puxada da própria parede. (RIBEIRO, 2016). 
O projeto de interiores realizado fez com que o conceito fosse ainda mais explorado pelo arquiteto. Os mobiliários criados parecem pertencer àquela "atmosfera" que se remete ao crustáceo marinho, como pode ser visto na cozinha e banheiro, onde os revestimentos relembram a formação da superfície das conchas.

Assim como a apropriação do espaço estar relacionada à arte da cenografia, a criação do lugar como cena, também é mencionado por Urssi (2006). Sendo por definição do mesmo autor "o conceito de lugar como um conjunto de elementos coexistindo dentro de certa ordem que pode ser de caráter identificador, relacional e histórico" (URSSI, 2006, pg. 79), na Náutilos, o conceito de lugar é tomado pelo caráter relacional: a arquitetura está relacionada à forma de uma concha onde seu programa foi distribuído de forma livre pelo caracol.

A linguagem visual é também outra técnica abordada pela cenografia, pelo fato de causar sensações. Segundo URSSI (2006, pg. 79) a percepção das formas e do espaço são instantaneamente absorvidos e associados à inúmeras sensações, criando uma visão unificada e global. Assim, o elemento luz, aparece como um dos mais importantes elementos que compõe a cenografia, que segundo o mesmo autor, todo projeto de iluminação a ser aplicada, parte da necessidade dramatúrgica pelas características do momento cênico. "A percepção da luz enquanto dimensão cromática é sensorial e pode ser usada para expressar e intensificar a informação visual" (URSSI, 2006, pg. 91).

No projeto da Nautilus House, o arquiteto explora muito bem esse elemento. É o principal elemento de efeito visual provocado na sala da residência devido aos vitrais coloridos que se estendem por toda a superfície da fachada projetando um espectro de cores abundantemente vivas e calorosas em seu interior.

\section{ANALOGIA SOBRE O CONCEITO MATEMÁTICO}

Seguindo o conceito matemático, "O projetista estabelece a base de tomada de decisões arquitetônicas na matemática e na geometria, priorizando relações numéricas, conceitos de equilíbrio e proporção e princípios como a de pureza e perfeição" (SNYDER, CATANASE, 1984 apud CASTELNOU, A. 2016).

As formas arredondadas e curvas de sua arquitetura reinterpretam as conchas dos náutilos. Essa concha é sinônimo de perfeição, pois sua espiral corresponde a um logaritmo matemático. O interior é cheio de espirais, círculos e salas de forma orgânica que imitam as câmaras côncavas que se esperaria encontrar dentro de um molusco gigante. (ES.WIKIARQUITECTURA,2015).

Quando o bicho que vive numa concha cresce, é necessário que a concha onde vive também cresça, para o acomodar. 0 modo de crescimento das conchas permite que a sua forma se mantenha. As medidas dos segmentos que unem o centro da concha aos pontos da concha aumentam, mas as amplitudes dos ângulos formados por esses segmentos e as tangentes à concha mantêm-se, ou seja, as conchas seguem uma espiral equiangular ou logaritmica. Dado um ponto $O$, a espiral equiangular é uma curva tal que a amplitude do ângulo formado pela tangente em qualquer dos seus pontos $P$ com a recta OP é constante: (PICADO, J. 2006, p.1).

O retângulo áureo é qualquer retângulo $A B C D$ que se dele se suprimir um quadrado como $A B F E$, o retângulo restante $C D E F$ será semelhante ao retângulo original. Partindo de um retângulo áureo $A B C D$ podemos construir a espiral de ouro. (SERRES; MAGRO; AZEVEDO, 2016). 


\section{CONCLUSÃO}

Após a leitura e intepretação dos conceitos apresentados acima, foi possível entender o processo de criação do projeto arquitetônico da casa Nautilus e identificar ações e elementos que influenciaram o arquiteto a tomar partido pelas formas e pelas sensações que o interior causaria.

Baseada num elemento da natureza, a representação da residência pelo formato da concha do náutilos, trouxe os conceitos teatral e matemático em sua composição. Assim, Javier Senosiain, cria os caminhos em forma de espiral, mesclando a racionalidade matemática (proporção áurea) com as formas orgânicas da natureza encenando ambientes criativos: em cada passo o usuário vislumbra uma cena diferente.

A exploração da luz e da criação de cenários pelas formas orgânicas identificou o conceito teatral; e a aplicação matemática pela geometria da concha, que definiram os ambientes pelas câmaras internas do náutilos, identificou o conceito matemático. Desta forma, as analogias matemática e teatral se completam, proporcionando ao usuário uma vivência orgânica

São análises, estas, que permitem compreender as associações tipológicas que uma obra arquitetônica apresenta e entender que muitos conceitos aplicados, visíveis, ou não, à primeira vista, são fundamentais para se obter uma boa arquitetura, são eles que atribuem a obra uma significância ímpar à sua sociedade, aquilo que supera a simples definição de abrigo e lhe confere um caráter.

\section{REFERÊNCIAS}

ANDRÉ, M; LUDKE, M. Pesquisa em educação: abordagens qualitativas. São Paulo: EPU, 1986.

ARCHITECTUREARTDESIGNS. Nautilus shell house, wonderful project by Arquitectura Orgánica. Disponível em: <http://www.architectureartdesigns.com/nautilus-shell-house-wonderful-projectby-arquitectura-organica/>. Acesso em: 01 Ago. 2016.

CASTELNOU, A. Conceitos em Arquitetura. Disponível em: <http://arquitetoeurbanista.weebly.com/uploads/6/8/3/8/6838251/ta487_e-01a.pdf>. Acesso em: 02 Ago. 2016.

ES.WIKIARQUITECTURA. Casa Nautilus. Disponível <https://es.wikiarquitectura.com/index.php?title=Casa_Nautilus >. Acesso em: 01 Ago. 2016.

FRAMPTON, K. História crítica da arquitetura moderna. 3. ed. São Paulo: Martins Fontes, 2003.

GUEDES, F. Número de Ouro. Disponível em: <http://escolakids.uol.com.br/numero-deouro.htm>. Acesso em: 02 Ago. 2016.

JANSON, H. História geral da arte. 2 ed. Editora(s) Martins Fontes. 2001

PICADO, J. A Beleza Matemática das Conchas Marinhas. Disponível em: <http://www.mat.uc.pt/ picado/conchas/artigo.pdf>. Acesso em: 02 Ago. 2016.

RIBEIRO, D. Obvious. Nautilus shell house: uma casa de fantasia. Disponível em: <http://obviousmag.org/archives/2011/08/nautilus_shell_house_uma_casa_de_fantasia.html>. Acesso em: 31 jul. 2016.

SERRES; MAGRO; AZEVEDO. O Número de Ouro como Instrumento de Aprendizagem Significativa no Estudo dos Números Irracionais. Disponível em: 
<http://www.ufrgs.br/espmat/disciplinas/midias_digitais_II/modulo_IV/numero_de_ouro2.pdf>. Acesso em: 01 Ago. 2016.

SNYDER, J; CATANESE, A. Introdução à arquitetura. Rio de Janeiro: Campus, 1984. p. 160-223. Disponível em: <http://docslide.com.br/documents/introducao-a-arquitetura-snydercatanese.html\#>. Acesso em: 26 jul. 2006.

URSSI, N. J. A linguagem cenográfica. 2006. 122f. Dissertação (Mestrado em Artes) - Escola de Comunicação e Artes da Universidade de São Paulo, São Paulo - SP. Disponível em : < http://www.iar.unicamp.br/lab/luz/ld/C\%EAnica/Pesquisa/a_linguagem_cenografica.pdf $>$. Acesso em: 26 jul. 2006.

ZEVI, B. Saber ver a arquitetura. 5. ed. São Paulo: Martins Fontes, 1996. 